\title{
Los municipios de San Gabriel Chilac y San Juan Teotihuacan ante la federalización de las aguas, 1888-1960
}

\section{Jesús Edgar Mendoza García*}

CIESAS

A partir de un análisis comparativo sobre dos casos de pequeña irrigación en los municipios de San Gabriel Chilac en Puebla y San Juan Teotihuacan en el Estado de México, se muestra la diversidad de resultados que generó la política de centralización sobre el recurso hídrico que antes controlaba el ayuntamiento. De igual modo, se explican los factores socioeconómicos regionales que llevaron al gobierno local y a los actores sociales a negociar, adaptarse o resistir a tales políticas federales que disminuían sus prerrogativas, para finalmente señalar quienes fueron los beneficiarios directos del proceso.

(Centralización, aguas, ayuntamiento, actores sociales)

\section{INTRODUCCIÓN}

1 artículo 27 de la constitución federal de 1917 estableció que la propiedad del suelo y el subsuelo quedaría en manos de la nación y sólo ésta, a través del poder Ejecutivo, tendría la facultad de otorgar concesiones de su utilización. Este proceso de centralización significó "un despojo de facultades locales a favor del fortalecimiento de la instancia de gobierno que reclamaba de manera exclusiva la representación de la nación, el gobierno federal" (Aboites y Estrada 2004, 11). Sin embargo, el proceso no fue lineal ni completo, ya que los sectores afectados, tanto los individuos, como las empresas y los ayuntamientos intentaron evadir y retrasar la aplicación legislativa, en unas ocasiones negociaron y en otras hasta

*edgarmengar@hotmail.com 
opusieron una fuerte resistencia a la federalización. ${ }^{1}$ Lo que interesa destacar aquí es la diversidad de resultados que generó la política de centralización sobre el agua de los manantiales, uno de los recursos productivos que el ayuntamiento venía controlando desde el periodo colonial. Por tanto, es obligado analizar por lo menos dos regiones del país con condiciones similares que desde antaño contaban con sistemas hidráulicos de pequeño riego. ${ }^{2}$ En este caso me centraré en hacer un análisis comparativo no sólo sobre los avatares para imponer el proyecto federal tanto en el manantial La Taza ubicado en el municipio de San Gabriel Chilac, Puebla, como en los manantiales de Teotihuacan en el Estado de México, sino también para evaluar el impacto que tuvieron las normas legales sobre la administración del recurso hídrico, con el fin de conocer en qué medida disminuyeron los ingresos de las arcas municipales y quiénes fueron los beneficiarios directos de los cambios legislativos.

Desde mi punto de vista, el Estado federal impuso sus condiciones con mayor fuerza donde los empresarios nacionales y extranjeros tenían intereses y proyectos de irrigación de gran alcance, en cambio, donde las oligarquías regionales como hacendados, comerciantes, rancheros y campesinos comuneros tenían el control de la tierra, el agua y la producción local, fue más difícil llevar a cabo la centralización. Lo mismo sucedió con los ayuntamientos, allí donde éstos habían perdido el control del agua más bien se mostraron apáticos o hasta favorables a la intromisión federal, en cambio, en aquellos que todavía a estas alturas la administraban y obtenían ingresos importantes, mostraron una férrea batalla para defender sus anti-

${ }^{1}$ Por el concepto de federalización se debe entender el proceso impulsado por el Estado para tener bajo su control las formas de acceso, gestión y distribución de los recursos naturales del suelo y del subsuelo, en este caso, el agua y la tierra. En cambio, por nacionalización se entiende como la acción declarativa a través de una legislación o de una resolución presidencial donde el Estado determina en forma directa el acceso a dichos recursos. Una discusión más amplia sobre estos conceptos puede verse en Aboites 1998, 11-17.

${ }^{2}$ En México se distinguen dos sistemas de riego, la gran irrigación ubicada principalmente en el norte del país y la pequeńa irrigación que predomina en el centro y sur del país (Palerm et al., 2000, 32-35). 
guos derechos sobre las aguas que consideraban comunales. ${ }^{3} \mathrm{La}$ situación de San Gabriel Chilac y San Juan Teotihuacan, ambos con un sistema de pequeño riego, puede revelar otros mecanismos de este proceso. ¿Por qué el Ayuntamiento de Teotihuacan no opuso resistencia a la federalización y por el contrario, las autoridades locales de Chilac contra viento y marea, siguieron manejando las aguas hasta principios de la década de 1950? ¿Qué factores sociales, políticos y económicos retrasaron la formación de juntas de agua y en otras las impulsaron?

El trabajo se divide en dos partes, la primera ofrece un panorama de los antecedentes de cada región con el fin de conocer en manos de quienes estaba la administración del agua de los manantiales antes de 1917. La segunda analiza por separado la relación y tensiones que se presentaron entre la federación, las municipalidades y los actores sociales de Teotihuacan y Chilac como resultado de los decretos federales sobre las corrientes de agua. Es decir, se explicará cuáles fueron las causas para que en Teotihuacan el proceso fuera más rápido y en cambio en Chilac hubiera mayores problemas para establecer las reglas federales en cuanto a la nueva administración y manejo de las aguas de los manantiales hasta 1960. Aspectos que arrojarán nuevas luces para entender no sólo los cambios políticos, económicos y hasta ecológicos que trajo consigo la Constitución de 1917 y la reforma agraria sobre la estructura social y la administración del agua, sino también para comprender si en efecto se trataba de un Estado débil o de una constante negociación con la elites y grupos locales.

\section{El MEdio GEOGRÁFICO}

El municipio de San Juan Teotihuacan se ubica en la Cuenca del Valle de México y San Gabriel Chilac pertenece a la Cuenca del Alto Papaloapan. En el primero predomina el clima frío y templado semiseco, tiene una precipitación pluvial de mil milímetros anuales.

${ }^{3}$ A pesar de la legislación federal en materia hidráulica, algunos ayuntamientos lograron mantener el control de las aguas hasta la tercera década del siglo xx (por ejemplo, Chávez 2005, 20-29). 
Para principios del siglo xx, los cultivos más importantes eran maíz y trigo, la producción de pulque también tenía su relevancia. ${ }^{4}$ En el segundo, el clima es semicálido seco, su precipitación pluvial media varía entre los cuatrocientos y seiscientos milímetros cada año. ${ }^{5} \mathrm{Se}$ cultiva maíz, frijol y hortalizas. La introducción de nuevas siembras a fines del siglo XIX y primera mitad del XX, así como otras políticas estatales sobre el recurso hídrico y el reparto agrario transformaron la ecología y la economía de ambas regiones.

Desde antes de la conquista española, la agricultura de los pueblos de Teotihuacan dependía de la humedad de las lagunas del valle, en algunas zonas de la técnica chinampera y de la afluencia de pequeños ríos que provenían de las partes altas de Otumba. Para el siglo XIX, varias de estas lagunas se habían desecado, así que en este contexto los manantiales y pequeńos arroyos eran de vital importancia para el consumo humano y para irrigar tierras de cultivo. Sobre todo durante el porfiriato cuando se introdujeron nuevos cultivos como la alfalfa, cebolla y ajo que requerían mayores cantidades del vital líquido. La cercanía con la ciudad de México estimuló la producción lechera, fomentó la llegada de foráneos, lo que aceleró el mestizaje y la pérdida del idioma autóctono, por si fuera poco, la presencia de ranchos y haciendas impulsó el acaparamiento de la propiedad en manos de haciendas y generó nuevas formas de explotación de la mano de obra campesina. De igual modo, el arribo del ferrocarril, telégrafo y electricidad aumentaron las transacciones comerciales.

San Gabriel Chilac, ubicado en el suroeste del valle de Tehuacán estaba relativamente aislado del desarrollo porfirista, su población era predominantemente indígena y se continúa hablando el idioma náhuatl hasta el día de hoy. A fines del siglo xIx, la cercanía con la ciudad de Tehuacán, Puebla, afectó en menor grado su estructura tradicional. El agua de los barrancos sólo corría en temporada de lluvias, así que desde el periodo colonial dependieron de los manantiales, entre ellos uno muy importante conocido como La Taza.

\footnotetext{
${ }^{4}$ Gamio 1979, tomo III.

${ }^{5}$ Pérez (sf, 19-22).
} 


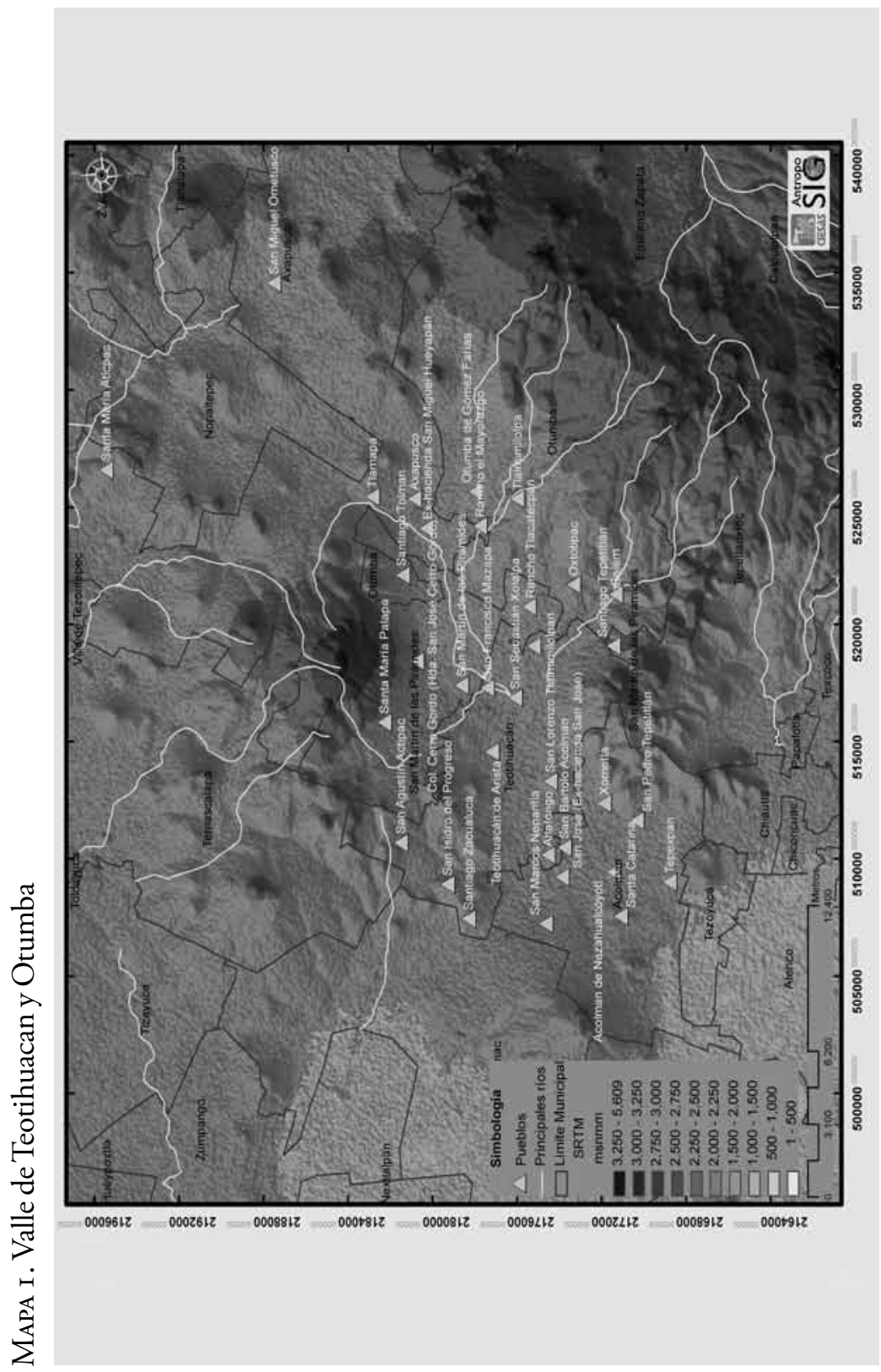


Aquí los cambios económicos se empezaron a notar hasta la década de 1930, cuando se introdujeron nuevos cultivos como ajo, cebolla, chile y elote, que se enviaron a los mercados de Tehuacán, Puebla y más tarde a la ciudad de México, lo que generó algunas transformaciones en el uso de tierras y aguas y propició enfrentamientos entre las elites locales, pequeńos propietarios, comuneros y ejidatarios por el control y reparto de las aguas del manantial. En este contexto se percibe la paulatina intervención del Estado para formar una junta de aguas y desplazar al ayuntamiento.

El siguiente apartado señala en manos de quienes estaban las aguas de los manantiales antes de decretarse la constitución de 1917, lo que también nos lleva a explicar desde cuando algunos ayuntamientos empezaron a perder su influencia en el control de las aguas comunales.

\section{Los manantiales de TeOtihuacan ANTES DE I9I7}

En el valle de Otumba y Teotihuacan existían dos sistemas de riego a fines del siglo XIX, el más importante y de tipo permanente era el que se originaba en los manantiales de San Juan Teotihuacan y que junto a las aguas del río San Lorenzo y San Juan irrigaban tierras de pueblos y haciendas. El segundo sistema provenía de las barrancas y era temporal, pues en tiempo de lluvias captaba las aguas broncas que descendían de las serranías de Otumba y Cerro Gordo, estas aguas eran retenidas por los hacendados en represas, cajas de entarquinamiento y luego conducidas por canales a los campos de cultivo (Birrichaga 2002, 11).

Como hemos dicho, los manantiales de Teotihuacan tienen su origen en el periodo prehispánico. ${ }^{6}$ Con la formación de pueblos de indios en los primeros años coloniales, dichas aguas permanecieron en manos de la república de indios de San Juan Teotihuacan. Pero conforme se fueron estableciendo haciendas españolas empezaron las disputas por el vital líquido entre éstas y los pueblos. En el trascurso del siglo Xvir pueblos y haciendas entablaron un largo litigio

\footnotetext{
${ }^{6}$ Sobre los canales de riego prehispánico, puede verse la obra de Doolitte, 2004.
} 
sobre las aguas de los manantiales que desembocaban en el río San Juan y San Lorenzo y que iban a dar al lago de Texcoco. Para solucionar las confrontaciones entre particulares y pueblos por el uso de las aguas, en 1684 el gobierno virreinal estableció el repartimiento para los distintos usuarios de la región:

El pleito sobre aguas que se decidió con repartirlas del río entre la Haciendas del licenciado don Antonio Flores, doña Juana María Pardo, padres de Oculman y barrio de San Bartolo, San Juanico, Santa María, Tenango, Calvario, San Miguel, San Pedro: pleito en que no litigó ni pudo litigar mi parte el pueblo de Teotihuacan. No litigó porque no se trataba de repartir las aguas que manan $[\ldots]$ sino en las que corren por el río. ${ }^{7}$

Las aguas de los manantiales que fluían al río San Juan y las que corrían por el río San Lorenzo fueron repartidas a varios pueblos y haciendas aledańas. En este pleito no participó San Juan Teotihuacan, lo que corrobora que las aguas que nacían en el fundo legal eran de su propiedad. En dicho repartimiento, el convento de Acolman obtuvo "dos surcos de aguas" que provenían del río San Juan, pero con la expulsión de los jesuitas, en 1767, estas aguas retornaron a los pueblos. Desde aquellos ańos se detecta que la mayor cantidad de surcos de agua quedó en manos de propiedades particulares. Para 1810 cuatro haciendas recibían 30 surcos y sólo dos permanecieron en poder de los pueblos de Xometla y Calvario (Birrichaga 2002, 12).

En 1818, los frailes del convento de San José Acolman entablaron un pleito por aguas en contra del pueblo de San Juan Teotihuacan. En su demanda argumentaron que dichas aguas les pertenecieron hasta 1767 , año en que se expulsó a la orden jesuita de la Nueva España, y desde entonces "los indios se habían quedado con ellas". Sin embargo, el "solicitador de indios", con base en la legislación indiana y de las siete partidas, argumentó una defensa hábil para demostrar que las aguas de los manantiales de Teotihuacan

7 "Contestación a la demanda sobre las aguas manantiales de este pueblo para el uso de la hacienda de San José Acolman”, AHMTEO, Fondo Justicia, 1818. 
eran del pueblo y no de la Compañía de Jesús. En primer lugar, señaló que era necesaria hacer la distinción entre aguas que manan y aguas que corren:

\section{Conforme a la documentación}

cuanto por su apoyo legal, que las aguas de los ojos son del pueblo de Teotihuacan porque allí nacen y manan y que los indios pueden conducirlas [...] por sus tierras para aprovecharse de ellas como mejor les convenga en virtud de aquellas leyes del reino conforme corran o fluyan a formar el río [...] haciéndose común a quienes son colindantes con sus riveras. Y esta distinción la hallamos en las leyes de Partida [...] la 6a dice que un río pertenece a todos los hombres comunalmente en tal manera que también pueden usar de ellos los que son de otra tierra extraña como los que moran o viven en aquellas tierras. He aquí la definición legal de agua que mana; y agua que corre. ${ }^{8}$

Después de ganar el pleito, las aguas de los manantiales permanecieron en manos del pueblo, pero no sabemos cómo funcionaba el reparto de las aguas al interior del mismo. Tenemos entendido que durante las primeras décadas del México independiente, los gobiernos locales mantuvieron en su poder la administración de los recursos comunales, entre ellos, las tierras, bosques, montes y aguas que anteriormente pertenecían a los pueblos de indios. ${ }^{9}$ En 1826 , San Miguel Xometla y sus barrios de San Pedro Tepetitlán y Santa María tenían asignados dos surcos, que se turnaban por tandas, ocho días a cada uno. ${ }^{10}$

La ley de desamortización de 25 de junio de 1856 afectó la propiedad comunal de los pueblos, pero la mayor parte de las aguas ya estaban en manos de propiedades privadas. En el archivo municipal

8 "Contestación a la demanda sobre las aguas manantiales de este pueblo para el uso de la hacienda de San José de Acolman”, AHMTEO, fondo Justicia, 1818.

${ }^{9}$ En el Estado de México la constitución estatal dejó en manos del ayuntamiento la administración y reglamentación de los propios y arbitrios con el fin de que el gobierno local obtuviera recursos económicos que le permitieran sufragar sus gastos administrativos (Birrichaga 2003; Sandre 2007, 42).

${ }^{10}$ AHA, Aprovechamientos Superficiales, c. 4482, exp. 59284, f. 41. 
de San Juan Teotihuacan hemos localizado una información muy completa de la adjudicación de las tierras de común repartimiento, pero hay pocos datos sobre el asunto de aguas. ${ }^{11} \mathrm{~A}$ principios del siglo xx, la tesorería municipal recibía una cantidad mínima por concepto de aguas. En el presupuesto municipal para el año 1902 se manifestó que ingresarían a la tesorería un monto anual por la suma de 3,739.90 pesos, de los cuales solamente se cobrarían cincuenta "Del acueducto de Maquixco para conducir el agua". ${ }^{12}$ Aunque no dice quien pagaba ese monto. Sin duda, una pequeña parte de las aguas de los manantiales se utilizaba para el uso público de la población, y la mayor cantidad era destinada para riego y estaba en manos privadas.

$\mathrm{Al}$ mismo tiempo se establecieron nuevas reglas legales. Como se sabe, la Ley General sobre Vías de Comunicación de 1888 inició la injerencia federal en materia de aguas, que se fue fortaleciendo conforme se emitieron otras leyes que iban encaminadas a centralizar las aguas en manos del gobierno federal. ${ }^{13}$ De todas estas leyes se derivó el concepto de que la propiedad privada del agua no existía y que sólo se tenía acceso a ella por medio de una concesión del gobierno federal. Así que todo aquel que quisiere hacer uso de las aguas federales debería pedir permiso a la Secretaría de Fomento. Entre 1900 y 1920, los hacendados y rancheros del valle de Teotihuacan solicitaron la confirmación sobre el uso de las aguas pagando sus cuotas correspondientes. Pero también hubo pueblos que pidieron al gobierno el reconocimiento de sus antiguos derechos. Por ejemplo, en 1905, los pueblos de El Calvario, San Bartolo y los barrios de Tenango y San Juanico entablaron un litigio en contra del pueblo de San Miguel Xometla porque desde 1855, este último les había qui-

${ }^{11}$ AHMTEO, Tierras, cs. 1 y 2, Adjudicaciones de tierras entre 1860 y 1872.

${ }^{12}$ AHMTEO, Tesorería, ańo 1901 ( también en 1899 aparece "por aguas, 50 pesos").

${ }^{13}$ La ley de 6 de junio de 1894 dejó en manos del gobierno federal la autorización de concesiones de agua para riego y electricidad; la ley de 7 de diciembre de 1896 tenía el propósito de resolver definitivamente los conflictos entre gobierno estatal, federal y los usuarios; la ley de 18 de diciembre de 1902 decretó que las aguas eran parte del patrimonio nacional; y finalmente la ley de aguas de 13 de diciembre de 1910 determinó que las aguas pertenecían a la federación y definió los distintos usos del agua (Cárdenas 1982; Aboites 1998, 85-89). 
tados las tandas que correspondían a los quejosos, argumentando que éstos no habían contribuido con su cuota para cubrir los gastos que originó un pleito por aguas contra San Juan Teotihuacan. Por lo tanto, solicitaban que el gobierno confirmara sus derechos al agua que les otorgó el gobierno virreinal en $1684 .{ }^{14}$ La Secretaría de Fomento señaló que se trataba de un asunto contencioso entre los derechos de los pueblos y que correspondía a los tribunales resolver la querella. No obstante, con base en el artículo 2o. de la ley de 5 de junio de 1888, solicitó a los pueblos litigantes que exhibieran sus títulos que les daban derechos para uso de dichas aguas. Después de recibir la documentación y analizarla, en 1908 llegó a la conclusión de que ambos pueblos tenían derecho según el reparto colonial de 1684, pero se negó la confirmación mientras no se resolviera el asunto en los tribunales correspondientes. Entre 1914 y 1918 los pueblos afectados siguieron presionando al gobierno para que reconociera sus derechos al uso de las aguas. Finalmente, el 16 de marzo de 1920 el presidente Venustiano Carranza confirmó los derechos a los pueblos de El Calvario, San Bartolomé, San Juanico y Tenango. Pese a esta declaración, los vecinos de Xometla, San Pedro y Santa María se opusieron tenazmente y todavía en 1924 seguían en posesión de las aguas. Para recibir su tanda de agua los pueblos afectados tuvieron que esperar hasta 1927 cuando se estableció un nuevo reglamento para la distribución de las aguas de los manantiales de San Juan Teotihuacan.

De estos hechos deducimos que hubo pueblos como Xometla que al igual que los hacendados se opusieron a la declaración de aguas federales y al reparto de aguas que afectaba sus intereses y se resistieron a perder el control del recurso hídrico en detrimento de otros pueblos que también fueron favorecidos desde 1684 .

Conforme las corrientes de agua; ríos, manantiales, lagos y lagunas fueron declaradas de propiedad federal, los hacendados alegaron que habían utilizado las aguas desde "tiempo inmemorial". Todavía el 2 de febrero de 1923, José Ortega Espinosa pidió confirmación de derechos para utilizar aguas de los manantiales de San Juan Teo-

\footnotetext{
${ }^{14}$ AHA, Aprovechamientos Superficiales, c. 4482, exp. 59284, fs. 7-12.
} 
tihuacan para irrigar 420 hectáreas de terrenos de las haciendas de su propiedad denominadas San José Acolman, San Juan Bautista, Tepexpan y San Simón Ixtapan, en su petición señaló que utilizaba 420 litros por segundo. Agregó que las restantes quedaban para las haciendas de San Antonio, Santa Catarina y los pueblos de Maquixco, Xometla y Tepexpan. ${ }^{15}$ Lo que confirma que para estos años la mayor parte de las aguas de los manantiales y barrancas estaban en manos de las haciendas.

Incluso otros pequeños manantiales como el de Tular de Amac que nacía en tierras de la hacienda la Cadena, fue declarado de propiedad nacional y sus aguas otorgadas a los vecinos del pueblo de Atlatongo. Ante estas acciones del gobierno federal, el hacendado Alberto de Abiega, promovió un juicio de amparo contra la Secretaría de Agricultura y Fomento (SAyF) y el poder Ejecutivo, argumentando la violación a los artículos 14, 16 y 27 de la Constitución de 1917. Pese a sus escrituras y sus esfuerzos legales, el amparo le fue negado. ${ }^{16}$

Cuando se inició el reparto agrario en la década de 1920, los hacendados libraron una doble batalla por medio de estrategias legales e ilegales para defender sus propiedades, pues los pueblos no sólo solicitaron tierras, sino también la dotación de aguas. Pese a que los hacendados (muchos de ellos extranjeros) utilizaron la ley de amparo y recurrieron al apoyo de la embajada de sus países, sólo retrasaron el proceso y después de largos litigios, finalmente en 1927 se logró constituir una Junta de Aguas de los manantiales de San Juan Teotihuacan. A partir de entonces se estableció un nuevo reglamento de su distribución y de las cuotas. Las aguas volvían a los lugareños pero no al ayuntamiento, pues la Junta de aguas quedaría bajo la batuta del gobierno federal. A diferencia de otros municipios del Estado de México (Chávez 2005; Camacho 2006, 268-270), el de San Juan Teotihuacan no mostró interés alguno por recuperar el control de las aguas que había perdido desde el siglo xIx. Otra cosa sucedería en el municipio de San Gabriel Chilac donde el gobierno local dependía en gran parte de los ingresos por el ramo de aguas.

${ }^{15}$ AHA, Aprovechamientos Superficiales, c. 917, exp. 13011, f. 76.
${ }^{16}$ AHA, Aprovechamientos Superficiales, c. 1670, exp. 24374, f. 33. 
El valle de Tehuacán cuenta con un clima seco semicálido, con escasos tres meses de lluvia al año. Así que durante la época colonial el desarrollo de la agricultura dependió de varios manantiales entre los que destacan El Riego, San Lorenzo, San Diego Chalma, Santa Cruz, San Pedro Acoquiaco, Atzompa, Cozahuatl y La Taza. Durante el periodo colonial se reconstruyeron varios sistemas de canales que encauzaban las aguas a las tierras de cultivo y que atravesaban tierras comunales y privadas, lo que generó constantes pleitos entre pueblos de indios y haciendas españolas (Salazar 2000).

El pueblo de San Gabriel Chilac se ubica al suroeste del valle de Tehuacán, estaba organizado en cuatro barrios: Tepetiopa, Medianía, Tlaconahua y Ecatzingo que aprovechaban el líquido del manantial La Taza. El agua era considerada propiedad colectiva de los habitantes y repartida por medio de tandas. En las cercanías de este pueblo se establecieron las haciendas de San Miguel y San Andrés que también utilizaban el agua del manantial La Taza cuyo caudal era de aproximadamente cien surcos. Incluso estas aguas alcanzaban para regar tierras de los pueblos vecinos de San Francisco Altepexi, Ajalpan y San Pedro Tetitlán (Salazar 2000).

En el México independiente, las constituciones estatales dejaron la administración de los propios y arbitrios en manos del ayuntamiento, donde la población del municipio era predominantemente indígena, ésta administró las tierras y aguas de acuerdo con sus costumbres e intereses. Por ejemplo, en el estado de Puebla, desde 1820 , se puso nuevamente en vigor la constitución gaditana, varios ayuntamientos constitucionales se crearon en el valle de Tehuacán, pero su forma de funcionar no quedó muy clara. Así que posteriores decretos, como el de 30 de marzo de 1826 y el 3 de noviembre, trataron de reglamentar los asuntos del gobierno local. Por un lado, esta desorganización política permitió que varias comunidades modificaran poco sus tradiciones, por otra, la población era mayoritariamente indígena en varios pueblos y allí el poder político continuó en sus manos. Por supuesto que los acontecimientos nacionales no repercutieron de igual forma en todos los pueblos del valle. De 


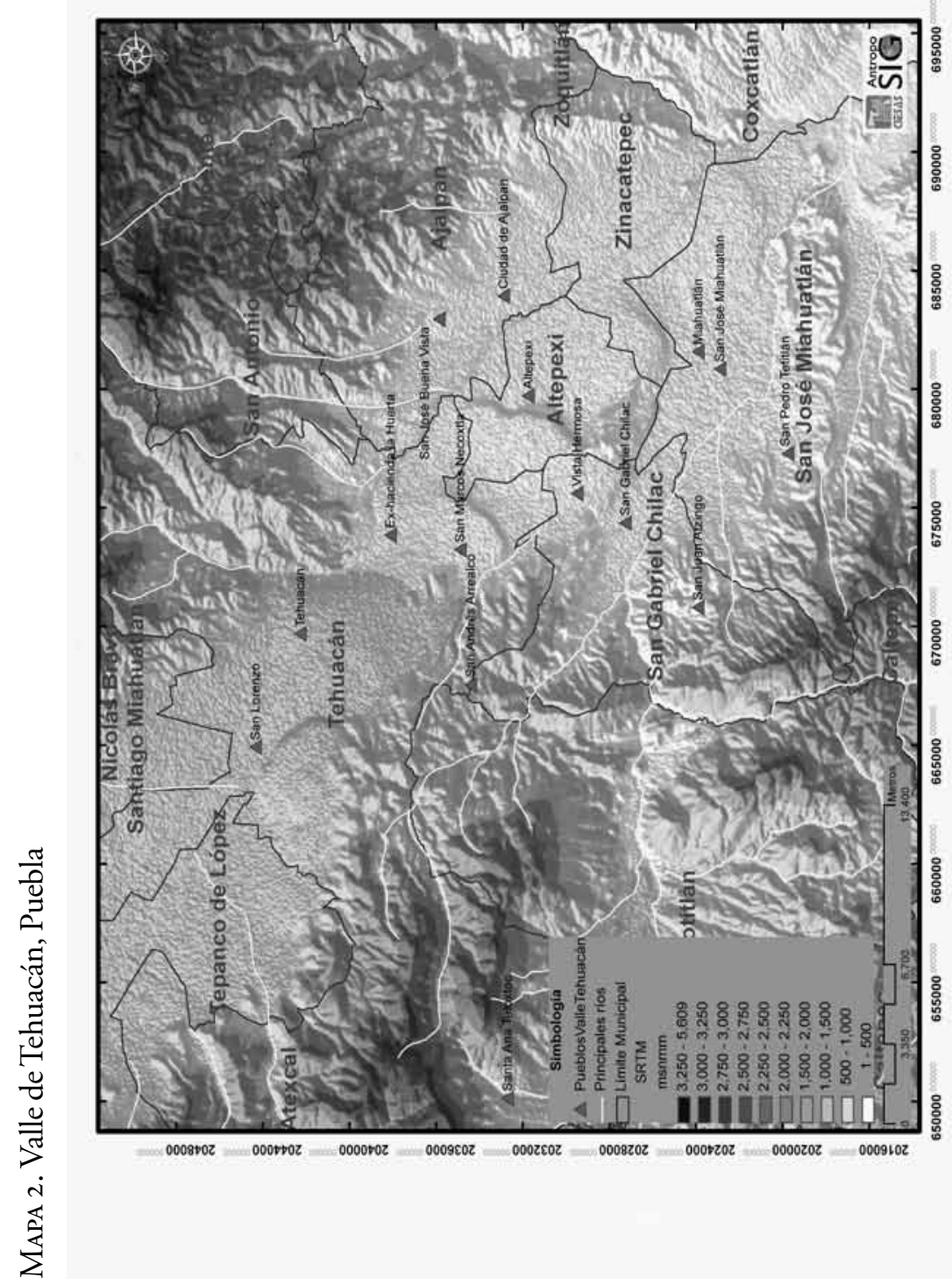


acuerdo con Emilio Henao, en el valle de Tehuacán se dieron dos procesos en torno a la organización y el control del agua. En Ajalpan se agudizó la división entre indios y mestizos, se incrementaron los conflictos por las tierras y el reparto del agua, dando por resultado que los mestizos desplazaran a los indígenas del manejo de estos recursos. ${ }^{17}$ En cambio, en Chilac y Altepexi donde la población indígena era mayoritaria, hubo más estabilidad y los indígenas siguieron controlando el gobierno local.

En los pueblos con mayoría indígena, el ayuntamiento asimiló la estructura comunitaria y fortaleció su organización cívico-religiosa. Tan es así que la organización del reparto del agua tomó tintes religiosos cuando las mayordomías empezaron a tener preponderancia en la administración y cuando el mayordomo se encargó de hacer el reparto de las aguas a los miembros; se daba agua a los comuneros siempre y cuando éstos cumplieran con sus obligaciones cívico-religiosas, es decir, mientras prestaran servicios a la comunidad y a la iglesia. Sin embargo, los mayordomos entraron en pugna con el ayuntamiento, pues según Henao, de todos los ingresos del ayuntamiento, $89 \%$ provenían de los fondos adquiridos por el pago y la renta de las aguas. El dinero obtenido por las aguas se ocupaba de la siguiente forma: para la subprefectura de Tehuacán $6 \%$; para la escuela $19.7 \%$; gastos administrativos del ayuntamiento $21.5 \%$; para la iglesia $24.6 \%$; para la banda de música $14.5 \%$; y para reparación de apantles y construcción de partidores de aguas $14.2 \%$. De ahí se comprende la importancia que tenían las aguas comunales para las arcas municipales.

En otras palabras, tanto el ayuntamiento de Ajalpan como el de San Gabriel Chilac seguían funcionando como en el periodo colonial, incluso compensaban con aguas a los funcionarios municipales por sus servicios, pues poseían un fondo de aguas que podían vender, rentar o gratificar a las personas. La cantidad que anualmente se recolectaba por concepto de aguas y otros ingresos menores se utili-

${ }^{17}$ En Ajalpan, el ayuntamiento continuó encargándose de la distribución de las aguas de los manantiales Apehualtia, Atiotlaquia, Agua de la Oración, Agua del Trapiche y Agua la Meza (Henao 1980, 91-92). 
zaba para cubrir los gastos administrativos. A pesar de la desamortización de las tierras comunales, de los problemas internos y la lucha entre indígenas y mestizos, los ayuntamientos de Ajalpan y San Gabriel Chilac siguieron distribuyendo el agua para riego y uso doméstico hasta el momento en que las aguas fueron declaradas de propiedad federal en la segunda década del siglo xx. Hasta entonces se darán algunas transformaciones que debilitaron la estructura comunitaria de riego en estas comunidades. Lo que refleja que la Ley General de Vías de Comunicación de 5 de junio de 1888 y otras leyes posteriores sobre aguas tuvieron escaso efecto en el sistema de riego de estos municipios poblanos.

Como han dicho algunos especialistas de los usos sociales del agua, la ley de 1888 inició la reglamentación por parte del gobierno federal, en un momento en que el asunto de las aguas llamaba la atención por que empezó a ser utilizada en grandes cantidades para generar energía eléctrica y regar abundantes extensiones de cultivo (Aboites 1998). En otras palabras, cuando se volvió un negocio redituable. Otro de los propósitos de tales medidas era liberar el capital y la circulación de mercancías de las trabas que generaban las jurisdicciones locales (Aboites y Estrada 2004).

A partir de entonces sería el gobierno federal el encargado de regular las corrientes que fueron declaradas nacionales, la ley de aguas de 1910 constituyó un paso más en este camino hacia la centralización del agua. Para culminar el proceso, el artículo 27 de la Constitución de 1917 centralizó el manejo de los recursos en manos del gobierno federal. Dicho artículo sometió a las principales corrientes fluviales a la jurisdicción federal al declararlas como propiedad de la nación, con lo que se puede decir que recuperó el dominio directo que en la época colonial habían ejercido los monarcas españoles (Castañeda 1995, 15).

En adelante las comunidades y usuarios de riego tendrían que solicitar a la federación la confirmación de sus derechos para el uso de las aguas, manifestando el volumen anual que utilizaban para que de acuerdo con ello la Secretaría de Hacienda hiciera el cobro respectivo. Sin embargo, en algunos lugares como en Camargo, Chihuahua, aunque el municipio perdió el manejo del agua, se con- 
virtió en un claro respaldo para solucionar los conflictos en las comunidades de riego. El presidente municipal declaraba abiertas las sesiones y ordenaba a la comisión de vigilancia rendir su informe a la asamblea general, a veces el propio presidente municipal pertenecía a una o dos comunidades de riego, de manera que el interés de las autoridades municipales era común con la conveniencia de las comunidades (Castañeda 1995, 64). De acuerdo con Castañeda, el poder federal no se manifestó de inmediato en todas las regiones. En un principio se limitó a recuperar los ingresos obtenidos por el pago de aguas que antes los usuarios daban al ayuntamiento, pero en otros casos, todavía aprobó reglamentos anteriores que beneficiaban a las elites locales y que habían sido confirmados por los gobiernos estatales.

En términos generales se puede decir que al iniciar el siglo xx, el dominio de las aguas tanto en el Valle de Tehuacán como de Teotihuacan estaba en manos de las oligarquías locales, los hacendados eran los principales dueños de la tierra y del agua desde el siglo XIX. En el municipio de Tehuacán, los hacendados habían construido galerías filtrantes para obtener más agua y ocuparla no sólo para la producción agrícola sino también para rentarla y hasta venderla al ayuntamiento, ejidatarios y fábricas (Mendoza 2005). El dominio que un grupo de terratenientes había logrado sobre los recursos del agua y la tierra era evidente en ambas regiones. El cambio de régimen de una propiedad corporativa a una propiedad liberal individual durante el siglo XIX sin duda tuvo un rol definitivo en la expansión de los latifundios. Pero como hemos visto, algunos pueblos y ayuntamientos conservaron sus derechos sobre el agua y siguieron organizando las faenas y cobrando impuestos a los usuarios. San Francisco Altepexi y Ajalpan mantuvieron bajo su control las aguas comunales hasta las primeras tres décadas del siglo xx, y el ayuntamiento de San Gabriel Chilac administró parte de las aguas del manantial La Taza hasta 1949. En suma, la historia colonial y decimonónica de cada manantial y ayuntamiento marcó las diferencias en el momento de llevarse a cabo la federalización de las aguas y el reparto ejidal agrario. 


\section{La Junta de Aguas de los manantiales de San Juan TeOtiHUaCAN, I929-1959}

Por mucho tiempo, el sistema de riego del Valle de Teotihuacan estuvo conformado por los ríos San Juan y San Lorenzo que recibían las aguas broncas del Cerro Gordo y las montańas de Otumba y junto con el agua de los manantiales del pueblo de San Juan Teotihuacan que desembocaban en el lago de Texcoco. En su largo recorrido irrigaban tierras de pueblos y haciendas, pero, en la segunda década del siglo xx, las aguas de los manantiales no sólo se encauzaron hacia las propiedades privadas sino también se construyeron nuevos canales para irrigar tierras ejidales y de pequeños propietarios, así lo menciona un documento de 1926:

En terrenos del pueblo de San Juan Teotihuacan brota una serie de manantiales siendo los principales el de La Parroquia, Los Ahuehuetes, Baño de los Caballos, cuyas aguas reunidas en dos canales principales van a dar, las unas a irrigar terrenos de las haciendas de Cadena y barrio de Maquixco por el canal conocido con el nombre de canal de La Cadena y las otras por un canal de sección muy irregular y sinuoso para ser llevadas a un deposito o partidor denominado Taza de Maquixco, del cual se derivan otros dos canales denominados San José y San Antonio. Del canal de San José hacen uso la hacienda la Cadena, los pueblos de Atlatongo, Tepexpan, Tequisistlán, Nexquipayac, Ixtapan, hacienda de Ixtapan y hacienda de San José, y del de San Antonio los pueblos de Xometla, El Calvario, Acolman y Hacienda de San Antonio. Hay que advertir que las aguas de esos manantiales primitivamente iban a dar al río San Juan y en él se confundían con las aguas torrenciales, para ir a dar al lago de Texcoco. Los canales de San José y San Antonio cambiaron el curso de las aguas de los manantiales llevándoselas a irrigar los terrenos de los usuarios mencionados. ${ }^{18}$

Como hemos dicho, las leyes porfirianas sobre aguas nacionales permitieron que muchos hacendados solicitaran la confirmación de sus derechos sobre las aguas de ríos, barrancas y manantiales en de-

${ }^{18}$ AHA, Aprovechamiento Superficiales, c. 417, exp. 7742, fs. 6-7. 
trimento de los pueblos aledaños. Pero cuando los ríos San Juan y San Lorenzo, así como los manantiales de San Juan Teotihuacan fueron declarados de propiedad nacional a principios de los veinte, ${ }^{19}$ los hacendados de La Cadena y Santa Catarina se opusieron argumentando que ellos habían solicitado la confirmación de sus derechos y que estaban pagando puntualmente sus impuestos.

Los problemas se agudizaron cuando muchos campesinos solicitaron no sólo la dotación de ejidos sino también las aguas. En estos años varias haciendas fueron afectadas por las resoluciones presidenciales. ${ }^{20}$ Los hacendados se ampararon y mostraron diversas estrategias de resistencia para proteger sus intereses y retrasar por varios años el reparto agrario. La década de 1920 fue de cambios y recomposición tanto en la tenencia de la tierra como del agua. Las tensiones entre haciendas y pueblos subieron al rojo vivo, en varias ocasiones los hacendados se aliaron con los presidentes municipales, el gobierno del estado y contaron con el apoyo de la comandancia militar para amenazar y disuadir a los campesinos.

El gobierno federal declaró de propiedad federal las aguas de los manantiales de San Juan Teotihuacan en 1920 y con el reparto de tierra también algunos pueblos lograron que se reconocieran sus derechos sobre aguas como Atlatongo, El Calvario, San Bartolo, Tenango, San Juanico, Tequisistlán, San Mateo Chiltepec, Cuanalán y Xometla (González 2000, 136).

En cuestión de aguas los problemas entre haciendas, ejidos y pueblos encontraron otras soluciones y tomaron nuevos rumbos cuando por intervención de la sayf y la Comisión Nacional Agraria en 1927 se hizo el primer Reglamento sobre el reparto de las aguas de los manantiales de San Juan Teotihuacan. ${ }^{21}$ De acuerdo con Margarita González "se dio paso a una nueva modalidad organizativa”,

${ }^{19}$ Las aguas del río San Juan Teotihuacan fueron declaradas nacionales por resolución presidencial publicada en el Diario Oficial el 21 de octubre de 1918; las de los manantiales de Teotihuacan el 14 de febrero de 1920; las del río San Lorenzo el 22 de agosto de 1922; y las del Tular de Amac el 26 de abril de 1923. AHA, Aguas Nacionales, c. 27, exp. 339, leg. 1, f. 36.

${ }^{20}$ AGA, Dotación de ejidos: El Calvario, Xometla, Cuanalán, Atlatongo, San Juan Teotihuacan, etcétera.

${ }^{21}$ AHA, Aprovechamientos Superficiales, c. 2419, exp. 34174, fs. 2-20. 
dado que en adelante ejidatarios y pequeńos propietarios desplazaron a los hacendados, y conformaron lazos intercomunitarios para la administración, conservación, distribución y vigilancia del sistema de agua para riego $(2000,136)$. Pero a partir de entonces surgieron otro tipo de problemas, ya no tanto entre haciendas y pueblos, sino entre ejidatarios, pueblos y pequeños propietarios.

La década de 1920 representa un parteaguas en el uso y la distribución de las aguas de los manantiales de San Juan Teotihuacan, dado que el número de usuarios aumentó notablemente. El reparto de las aguas fue más complejo y generó más conflictos sociales. En el reglamento de 1927 se incluyeron ejidos, pequeños propietarios, pueblos y haciendas y para 1932 tenemos a los siguientes usuarios.

Cuadro i. Distribución de aguas de los manantiales de San Juan Teotihuacan, 1932

\begin{tabular}{lrrr}
\hline Demarcaciones Usuarias & $\begin{array}{c}\text { Volúmen } \\
\text { metros } \\
\text { cúbicos }\end{array}$ & $\begin{array}{c}\text { Cuota } \\
\text { mensual }\end{array}$ & $\begin{array}{c}\text { Cuota } \\
\text { anual }\end{array}$ \\
\hline 1 Pequeños propietarios Calvario Acolman & 767,172 & 3.89 & 46.57 \\
2 Ejido de Calvario Acolman & $1,082,053$ & 5.47 & 65.70 \\
3 Ejido de San Juan Teotihuacan & 259,236 & 1.31 & 15.74 \\
4 Pequeños propietarios San Bartolo & 491,182 & 2.49 & 29.82 \\
5 Ejido San Bartolo Acolman & $1,161,871$ & 5.88 & 70.55 \\
6 Pequeños propietarios Barrio San Juanico & 118,568 & .50 & 7.19 \\
7 Ejido de Santa María & 357,334 & 1.81 & 21.69 \\
8 Ejido de Atlatongo & $1,410,323$ & 7.14 & 85.62 \\
9 Pequeños propietarios Xometla & 497,446 & 2.52 & 30.20 \\
10 Ejido de Xometla & $1,010,031$ & 5.11 & 61.32 \\
11 Ejido San Pedro y ampliación & 209,792 & 1.06 & 12.74 \\
12 Ejido de Cuanalán & $1,888,029$ & 9.55 & 114.62 \\
13 Ejido San Mateo Chipiltepec & 253,049 & 1.28 & 15.36 \\
14 Ampliación ejido San Marcos & 248,244 & 1.26 & 15.07 \\
15 Pequeños propietarios Santa Catarina & 406,500 & 2.06 & 24.68
\end{tabular}


Cuadro i. Distribución de aguas de los manantiales de San Juan Teotihuacan, 1932 (continuación)

\begin{tabular}{lrrr}
\hline \multicolumn{1}{c}{ Demarcaciones Usuarias } & $\begin{array}{c}\text { Volúmen } \\
\text { metros } \\
\text { cúbicos }\end{array}$ & $\begin{array}{c}\text { Cuota } \\
\text { mensual }\end{array}$ & $\begin{array}{c}\text { Cuota } \\
\text { anual }\end{array}$ \\
\hline 16 Ejido de Santa Catarina & 474,768 & 2.40 & 28.82 \\
17 Pequeños propietarios Tepexpan & $1,132,615$ & 5.73 & 68.76 \\
18 Ejido de Tepexpan & 691,981 & 3.50 & 42.00 \\
19 Pequeños propietarios Tequisistlán & 406,500 & 2.06 & 24.68 \\
20 Ejido Tequisistlán & 750,940 & 3.80 & 45.59 \\
21 Pequeños propietarios Nexquipayac & 490,283 & 2.48 & 29.76 \\
22 Ejido Nexquipayac y ampliación & 943,329 & 4.77 & 57.27 \\
23 Pequeńos propietarios Ixtapan & 366,160 & 1.85 & 22.23 \\
24 Ejido de Ixtapan & $1,424,303$ & 7.21 & 86.47 \\
25 Hacienda de Ixtapan & 297,893 & 1.51 & 18.08 \\
26 Hacienda de Cadena & 124,540 & .68 & 8.17 \\
27 Hacienda de Santa Catarina & 787,262 & 3.98 & 47.79 \\
28 Hacienda de San Antonio & 38,931 & .20 & 2.36 \\
29 Hacienda de San José & 55,855 & .28 & 3.39 \\
30 Hacienda de Tepexpan & 62,061 & .32 & 3.76 \\
Total & $18,208,251$ & 92.1 & 1,106 \\
\hline
\end{tabular}

Fuente: AHA, Aprovechamientos Superficiales, c. 2784, exp. 38974, f. 6.

Al observar la nueva distribución de las aguas de los manantiales de San Juan Teotihuacan, es notorio que se habían multiplicado el número de regantes, pero ahora en tres grupos: ejidatarios, pequeńos propietarios de los pueblos y haciendas. En este proceso del reparto de ejidos y dotación de aguas, las haciendas perdieron su hegemonía y el control sobre el vital liquido.

En adelante el dinero generado por cuotas de los regantes ingresaría a la tesorería de la Junta de Aguas y sería utilizado para pagar al presidente que anualmente tenía una "gratificación" de 240 pesos, el secretario y el tesorero ganaban ciento sesenta cada uno y dos distri- 
buidores de aguas con un sueldo cada uno de doscientos cuarenta y cuatro pesos anuales, el resto se ocupaba en gastos de escritorio y gastos extraordinarios. La superficie para riego era de 2,080.26 hectáreas, de las cuales $50.8 \%$ pertenecían a los ejidos; $29.3 \%$ se clasificaron como de pequeña propiedad y sólo $20.0 \%$ quedó en manos de las haciendas. ${ }^{22}$

A pesar de que en dos ocasiones el gobierno federal propuso otros reglamentos para mejorar la distribución de aguas e incluir a nuevos regantes, los usuarios rechazaron las decisiones federales y el reglamento de 1929 prevaleció con pocos cambios hasta 1959. Lo que corrobora que el Estado no siempre pudo imponer sus decisiones (Aboites 2009, 45-54). De acuerdo con Margarita González, pese a la injerencia federal la Junta de Aguas de los manantiales logró cierto grado de autonomía y autogestión para resolver los problemas locales (2000, 145-146).

La Junta de Aguas estaba integrada por 13 representantes ejidales, nueve pequeños propietarios y seis hacendados, todos con su respectivo suplente. Esta representación de varias comunidades fue encabezada por un presidente, un secretario, un tesorero y dos vocales. Asimismo, se integró un comité ejecutivo de vigilancia. En el Reglamento se especificaron las facultades de la Junta, sus obligaciones eras las siguientes: administrar y distribuir el agua equitativamente, organizar las tareas de limpieza y mantenimiento de los canales, actuar como árbitro en las disputas entre los usuarios y sancionar a quienes infringieran las reglas. Sin embargo, la Junta no podía alterar la distribución de las aguas y tampoco podía construir obras nuevas en la infraestructura hidráulica, pues estas últimas correspondían a la SAyF y a la Comisión Nacional Agraria. ${ }^{23}$

En el reglamento se reconoció una superficie de riego superior a la capacidad de los manantiales de San Juan Teotihuacan, lo que generó constantes problemas y exigencias por parte de los usuarios que tenían derecho a riego y que no siempre recibían su tanda. Otro problema fue el establecimiento de dos formas de distribución del

${ }^{22}$ AHA, Aprovechamientos Superficiales, c. 2419, exp. 34174, f. 16.

${ }^{23}$ AHA, Aprovechamientos Superficiales, c. 2419, exp. 34174, fs-6-12. 
agua, ya que se reconocieron derechos de agua continua a las comunidades de San Juan Teotihuacan, Atlatongo y Tepexpan y en cambio a los demás usuarios estarían bajo el sistema de tandas. Esta situación provocó conflictos intercomunitarios entre los pueblos que se localizaban aguas arriba frente a los que se localizaban aguas abajo. Por ejemplo, Atlatongo tenía una posición estratégica en el sistema de riego pues se ubicaba muy cerca de la tasa repartidora, así que en muchas ocasiones sus vecinos fueron acusados por desviar las aguas para regar ilegalmente sus tierras en perjuicio de otros regantes que con frecuencia elevaron sus quejas a la Junta de Aguas y a la Secretaría de Recursos Hidráulicos (SRH), solicitando se desconocieran los derechos de agua continua que tenían dos pueblos. A pesar de que el pueblo de Atlatongo fue sancionado con multas por la Dirección General de Aguas en 1946, las medidas impuestas fueron insuficientes para impedir despojos y robos de agua y, por tanto, los conflictos continuaron (González 2000, 158-162).

A mediados del siglo xx, se empezaron a construir pozos artesianos para obtener mayores volúmenes de agua para irrigar terrenos de cultivo y también para los usos domésticos de una población en constante aumento. Por si fuera poco, nuevos núcleos urbanos y colonias ejidales exigieron derechos sobre las aguas de los manantiales, a tal grado que las aguas fueron disminuyendo paulatinamente hasta secarse finalmente en 1991. El sistema de riego milenario de San Juan Teotihuacan no pudo soportar los usos y abusos de la población y de otros factores del progreso. Situación que contrasta con el manantial la Taza de Gabriel Chilac que hasta el día de hoy se mantiene, sin que esto implique ausencia de otro tipo de problemas.

\section{El ayuntamiento de Chilac contra el gobierno federal y la Junta de Aguas}

La nacionalización de las corrientes de agua fue percibida como una intromisión y un despojo del gobierno federal a los gobiernos locales, según Aboites y Estrada, "En varios municipios los pobladores y autoridades se toparon con la novedad de que sus aguas ya no eran suyas y en consecuencia, no podían administrarlas, concesionarlas o 
reglamentarlas, tampoco resolver disputas. Todas estas atribuciones quedaban en manos de una autoridad extralocal, el gobierno federal a través de de la SAyF, y en algunos casos cuando existían ejidos, de la Comisión Nacional Agraria” (Aboites y Estrada 2004, 20). Esta pérdida se notó principalmente en el área fiscal de algunos ayuntamientos, pues la tesorería dejó de recibir ingresos por arrendamientos, cuotas y multas. Por ejemplo, todavía en 1920 varios municipios que se asentaban en las riberas de los ríos Magdalena y Sonora captaban $40 \%$ de sus ingresos del ramo de aguas (Aboites y Estrada 2004, 24-25). En Todos Santos, Baja California Sur, el agua constituía la principal fuente de ingresos (Aboites y Estrada 2004, 142144). Lo mismo sucedía en San Gabriel Chilac, donde una parte importante de sus divisas provenía de las cuotas y arrendamientos de aguas. $^{24}$

La declaratoria presidencial obligaba a las autoridades y grupos locales a someterse al gobierno federal. Sin embargo, como veremos, la reacción de las autoridades municipales varió según sus circunstancias. En algunos casos los ayuntamientos optaron por acatar las nuevas reglas legales. Así ocurrió en Teotihuacan donde el gobierno local no tenía nada que perder, pues desde el siglo XIX el control sobre las aguas estaba en manos de particulares. Otros municipios en cambio, intentaron conservar sus facultades y solicitaron al gobierno federal la confirmación de sus derechos, de la misma forma como lo estaban haciendo empresas, hacendados y rancheros. Por ejemplo, Zacatlán en el estado de Puebla, solicitó la concesión sobre algunos manantiales que poco antes consideraba como de su propiedad (Aboites y Estrada 2004, 23). Lo mismo hizo San Gabriel Chilac en 1929 y 1947 cuando se percató de que era la única forma de mantener las aguas en su poder, pero para entonces los tiempos y las reglas habían cambiado.

El proceso de federalización de las corrientes de agua en el Valle de Tehuacán fue más tardío que en Teotihuacan y en Otumba, pero en general las elites opusieron una resistencia enorme que iba desde

${ }^{24}$ Entre 1917 y 1929 además de la nacionalización, el gobierno federal estableció un impuesto por el uso de las aguas nacionales. Es decir que la nacionalización también tenía la prioridad de cobrar impuestos (Herrera y Lasso 1994, 187-200; Aboites 1998, 94-96). 
amenazas, simulaciones, evasiones, fraccionamiento de sus propiedades, hasta recursos legales como la ley de amparo. La diferencia la encontramos en el nivel del gobierno local, pese a que en ambas regiones los intentos de federalizar las corrientes se iniciaron en la década de 1920, en Teotihuacan se formó la Junta de Aguas en 1927, en tanto que la federalización del manantial La Taza se efectuó hasta 1946 y la formación de una junta de aguas sólo fue posible a fines de 1948.

Cabe señalar que tanto la legislación porfiriana como posrevolucionaria en materia de aguas era conocida por los pueblos, pero éstos ocultaron la información a las instancias de gobierno y a veces interpretaron la ley de diferente forma. En agosto de 1929, el presidente municipal de San Gabriel Chilac envió un oficio a los barrios de Tepetiopa, Tlacozahuac, Medianía y Ecatzingo, para que nombraran su respectivo representante, y solicitaran ante la SAyF la confirmación de sus derechos al uso de las aguas del manantial Texcali. Una vez que se hizo el nombramiento, los representantes de los cuatro barrios hicieron la solicitud correspondiente y manifestaron que dichas aguas las habían usado para riego de terrenos particulares desde 1543 según sus títulos primordiales, lo que no era correcto pues más bien eran aguas y tierras comunales. Asimismo, señalaron que regarían una superficie de 1,481 hectáreas de propiedad particular. ${ }^{25}$ Para sustentar su petición anexaron una copia certificada de la Cédula Real de la fundación del pueblo de San Gabriel Chilac, copia del convenio celebrado en 1847 entre Chilac, San Pedro Tetitlán y San Mateo Tlacoxcalco, así como el acta de nombramiento de los representantes de los cuatro barrios. ${ }^{26}$ La solicitud fue rechazada por la SAyF porque no cumplía con los requisitos, así que los trámites se detuvieron hasta que se comprobara la propiedad del manantial. Por otra parte, la solicitud de los derechos a las aguas para usos públicos y domésticos debía ser presentada por el Ayuntamiento de San Gabriel Chilac y no por los representantes de los barrios. Es por

${ }^{25}$ Para estos años se percibe que los terrenos “antes de común repartimiento” eran propiedad privada en San Gabriel Chilac, lo que probablemente tiene su explicación en la aplicación de las leyes de desamortización desde la segunda mitad del siglo XIx. Pero llama la atención que las aguas fueran consideradas como comunales.

${ }^{26}$ AHA, Aprovechamientos Superficiales, c. 1341, exp. 18261. 
ello que el 10 de octubre del mismo año, el presidente municipal Francisco Martínez solicitó la confirmación al uso de las aguas para abastecer dieciocho fuentes con sus respectivos bebederos en varios lugares del pueblo, solicitando dieciséis litros por segundo, para una población de 5,872 habitantes, 1,200 cabezas de ganado mayor, 1,300 de ganado asnal y 3 mil de ganado cabrío. ${ }^{27}$

Asimismo, el 14 de octubre, una vez más, los representantes de los cuatro barrios se dirigieron a la SAyF, señalando que en caso de obtener la confirmación, ellos únicamente eran "simples representantes de la comunidad, sin derechos personales", y por tanto manifestaron: "La administración de las aguas a que la solicitud se refiere ha estado y está a cargo del municipio de este pueblo, como único y genuino representante de los intereses colectivos de la población. Será pues el municipio quien, después de la confirmación seguirá administrando". 28

Como se percibe, los representantes de los barrios no entendieron la nueva legislación sobre aguas federales y pretendieron conservar su antigua organización, donde el municipio seguiría siendo el representante y administrador de las aguas. Lo mismo sucedía en otras latitudes, en Chihuahua un número importante de pequeños propietarios seguían inscritos dentro del régimen municipal. No era extrańo para los comuneros y hasta pequeños propietarios, pues el manejo de las aguas había estado en manos del gobierno local desde por lo menos 300 años atrás, y esta actitud era comprensible.

El ayuntamiento de San Gabriel Chilac abandonó los confusos trámites burocráticos y en los siguientes veinte años siguió administrando las aguas del manantial. Sin embargo, conforme pasó el tiempo fueron surgiendo oposiciones internas que empezaron a cuestionar su representación por considerar que se trataba de aguas federales. Por ejemplo, en 1937, la autoridad municipal fue acusada por la "Sociedad Agrícola de Riego 'Benito Juárez", quien solicitó a la SAyF que enviara un comisionado para observar el funcionamien-

${ }^{27}$ AHA, Aprovechamientos Superficiales, c. 1739, exp. 25725. Octubre 29 de 1929. El presidente señaló que en el pueblo existían personas que contaban con 400 o 500 cabezas de ganado, sin anotar los porcinos que también había.

${ }^{28}$ AHA, Aprovechamientos Superficiales, c. 2020, exp. 30410. 
to de "las aguas comunales", pues existían varios inconformes por el reparto del vital líquido, a tal grado que "hubo heridos y descalabrados por causa del agua de Coxcahuatl”. Asimismo, pedía que se investigara si existían convenios entre el presidente municipal, el expresidente de la sociedad, el presidente del banco y el visitador. Pues era "extrańo que se volvieran a mezclar las aguas de la sociedad con el agua comunal". Como la acusación no era clara, la sAyF envió un ejemplar de la ley de aguas vigente, "para que en caso de que no concordara con su reglamento se hiciera la demanda respectiva" ${ }^{29}$

No sabemos qué paso en los siguientes años, pero fue hasta el 29 de marzo de 1946 cuando el manantial La Taza fue declarado como de propiedad nacional. Ante tales actos que ponían en peligro la autonomía local, el presidente municipal Faustino Alatriste promovió un juicio de amparo en contra del presidente de la república, la SRH y el delegado poblano, pero el juez segundo de distrito negó dicho amparo. ${ }^{30}$ Sin embargo, con el decreto federal, los usuarios reiniciaron los trámites para obtener la confirmación de sus derechos al uso de las aguas. Para el ayuntamiento, el desplazamiento significaba la pérdida del control social y la disminución de sus ingresos económicos, por estas razones entabló una lucha desigual en contra de la ley, la Junta de Aguas y la federación.

El manantial La Taza tenía un repartidor y varios canales, algunos de los cuales irrigaban tierras de los pueblos de San Francisco Altepexi y Ajalpan, quienes también se apresuraron a confirmar sus derechos sobre las aguas que utilizaban para riego. Una solicitud fue presentada el 22 de mayo de 1946 por el ciudadano Rafael Hernández a nombre de once vecinos del municipio de San Francisco Altepexi, para regar los terrenos denominados El Silvato, Casahuico, Zoyatla, Apancuitlapa, el Cañon, Acololco y el Cuarto.

El presidente municipal de San Gabriel no se quedó atrás y el 4 de junio de 1947 hizo una solicitud al gobierno, para obtener aguas para usos públicos y domésticos de la población. ${ }^{31}$ Casi al mismo

${ }^{29}$ AHA, Aprovechamientos Superficiales, c. 2020, exp. 30410.

${ }^{30}$ AHA, Aguas Nacionales, c. 1972, exp. 27733, leg. 1. La resolución sobre la solicitud de amparo se dictó el 28 de junio de 1948.

${ }^{31}$ AHA, Aguas Nacionales, c. 1580, exp. 21961, leg.1. 
tiempo, los usuarios de los cuatro barrios se organizaron para formar una asociación y solicitar la confirmación de sus derechos. Pero como el título de propiedad presentado no tuvo validez legal, como lo disponía la fracción iv del artículo 44 del reglamento de la ley de aguas vigente, se exigió a los solicitantes que presentaran sus títulos traslativos de dominio o bien un padrón expedido por la Oficina de Contribuciones, debidamente legalizado por el gobierno del estado. Los usuarios enviaron copia certificada de sus documentos a la SRH para su dictamen y reconocimiento legal.

Como los trámites de inspección y reglamentación se prolongaron, surgieron dos grupos antagónicos que se disputaron el uso de las aguas del manantial La Taza en el pueblo de San Gabriel Chilac. Por un lado, 600 usuarios de los cuatro barrios formaron a fines de 1948 una Junta Auxiliar de Aguas que al ańo siguiente fue reconocida por la Secretaría de Recursos Hidráulicos y, por otro, el presidente municipal y 280 seguidores nombraron otra Junta de Aguas presidida por Julián Bravo y expresidentes municipales.

La Junta Auxiliar de Aguas y el grupo minoritario se acusaron mutuamente ante las instancias superiores. Algunos ejemplos ilustran esta división. Emiliano Hernández, representante de la unión de usuarios insistió ante la SRH la confirmación de derechos al uso de las aguas porque "en la actualidad el ayuntamiento del pueblo de Chilac sin derecho alguno viene imponiendo gabelas indebidas a los usuarios". Pero el presidente municipal impidió las reuniones de los usuarios e incluso hizo prisionero a Hernández y al comisionado especial Zenón Escobedo, ${ }^{32}$ lo que refleja una pugna interna entre los líderes locales, pues Escobedo había ocupado el cargo de presidente municipal en varias ocasiones y al ser desplazado de la presidencia, se apoderó de la Junta de Aguas y desde allí intentó controlar la vida política y económica del municipio. ${ }^{33}$

A pesar de la declaratoria sobre el manantial La Taza y de la formación de la Junta de Aguas, el nuevo presidente municipal, Taurino Martínez Álvarez siguió cobrando cuotas a los usua-

\footnotetext{
${ }^{32}$ AHA, Aguas Nacionales, c. 1580, exp. 21961. 2 de marzo de 1947.

${ }^{33}$ AHA, Aguas Nacionales, c. 1976, exp. 27733, leg. 27.
} 
rios. ${ }^{34}$ Por ello, entre 1949 y 1953 , los representantes de los cuatro barrios se dirigieron a la SRH y hasta al presidente de la república, para denunciar las irregularidades, exigir la reglamentación de los usos de agua del manantial La Taza y acusar a las autoridades locales por desconocer las disposiciones federales. "Ya que los fondos que recauda la tesorería municipal no se destinan a la reparación de las escuelas, a las limpias de las cañerías, a la reparación de las mismas, sino que se distraen en atenciones de índole política que ningún beneficio reporta a la población". Sin embargo, el grupo minoritario respaldado por las autoridades municipales continuó obstaculizando las funciones de la Junta auxiliar reconocida por la SRH, y aunque esta última logró que se reconociera su legalidad, al intentar recuperar las aguas que tenían en poder los funcionarios municipales, se presentaron los opositores y junto con la policía impidieron el traspaso. Entonces Hernández una vez más acusó a las autoridades municipales de "sinarquistas" y de impedir la posesión de las aguas que pertenecía a la Junta, en respuesta el ayuntamiento culpó a Hernández de corrupción y malos manejos.

Entre los usuarios opositores, había 50 personas que poseían tieras de riego pero no contaban con sus títulos de propiedad, otros en cambio tenían tierras pero quedaron fuera de la zona de riego, otros más tenían derechos antiguos al uso de aguas pero no gozaban de terrenos. Todos estos usuarios y otros que querían integrarse enviaron copias de escrituras de predios urbanos, pero después del dictamen fueron excluidos del padrón y en consecuencia del reglamento. ${ }^{35}$ De ahí se comprende su rebeldía y apoyo incondicional al ayuntamiento, pues a través de esta instancia de gobierno local esperaban obtener justicia. Vale la pena citar la queja que dońa María Isabel Valdez Vda. de Garmendia hizo contra la Junta Auxiliar, señaló que desde 1911 había recibido una tanda de aguas, pero en la delimitación de la zona de riego, que llevó a cabo la Junta y la SRH, su predio había quedado fuera y excluido del reparto de aguas, a

${ }^{34}$ El decreto sobre la declaración de las aguas del manantial La Taza se publicó el 6 de junio de 1946, t. clvL, del Diario Oficial de la Federación.

${ }^{35}$ AHA, Aguas Nacionales, c. 1976, exp. 27733, leg. 27. 
pesar de tener escrituras que la acreditaban como dueña. En su demanda acusó de despotismo y egoísmo al expresidente de la Junta, Froylan Martínez y a su secretario, pues "arbitrariamente incluyeron en el reparto a sus hijos y nietos y dejaron a varios usuarios antiguos fuera del padrón”. Lo mismo sucedía con la nueva Junta presidida por Sabino Rodríguez e Hipólito Romero, quienes desde su punto de vista:

Todos eran asesorados por el usuario y empleado actual de la citada Junta, el señor Zenón Escobedo, este último expulsado por la presidencia municipal después de 32 años en el poder acompañado siempre en diferentes periodos con sus satélites nombrados que actualmente bajo su poder evolucionan los mismos en la referida Junta. Dicha aseveración es contundente en contra de las arbitrariedades de este cacique porque todos sin excepción han sido en otras épocas presidentes municipales y en la actualidad por no convenir a sus intereses son enemigos acérrimos de las autoridades municipales en funciones. ${ }^{36}$

El documento refleja la profunda división y la lucha sin cuartel que se libraba entre los principales líderes locales, unos se refugiaron en la Junta Auxiliar y otros se pertrecharon en la presidencia municipal y desde esos cotos de poder se atacaron unos a otros en menoscabo del funcionamiento de la asociación de usuarios. Todavía en 1953, Zenón Escobedo firmaba como "oficial mayor de la Junta" y sin duda era un hombre muy influyente en las decisiones de la misma. ${ }^{37}$

El ayuntamiento justificaba su participación en la administración de las aguas del manantial por que contaba con el reconocimiento del gobierno del estado de Puebla que había aprobado el presupuesto para el año 1948-1949 donde se incluía el ingreso por ese recurso. Otro de los factores que explican la resistencia a perder el control de las aguas se debía a que bajo el régimen comunal y la administración municipal era costumbre que los funcionarios municipales fueran compensados por sus servicios con una tanda de

${ }^{36}$ AHA, Aguas Nacionales, c. 1976, exp. 27733, leg. 27.
${ }^{37}$ AHA, Aguas Nacionales, c. 1976, exp. 27733, leg. 29. 
agua, sin importar si éstos tenían tierras de riego o no, incluso recibían su tanda y la podían vender. Pese a las divisiones internas y el reconocimiento de la Junta Auxiliar de Aguas del manantial La Taza, los miembros del ayuntamiento intentaron conservar su tanda de aguas por sus servicios en el gobierno local, aunque para ello tuvieron que despojar de sus aguas a los usuarios reconocidos, lo que mantuvo al rojo vivo los conflictos entre estos dos grupos antagónicos durante varios años.

Las quejas por despojo de aguas fueron muy frecuentes. En 1951, el presidente municipal Severiano Alatriste, así como los expresidentes Taurino Martínez y Faustino Alatriste con otros seguidores, el cuerpo de policías armados y otro grupo comandado por Julián Bravo disgustado con la unión de usuarios retaron a la Junta Auxiliar de Aguas y "pistola en mano al frente de veinte armados" impidieron el reparto de aguas. ${ }^{38} \mathrm{El}$ motivo era porque no se respetaba la costumbre, ya que cuando moría algún usuario sin herederos, el municipio reclamaba la tanda del difunto y la concedía a algún miembro del ayuntamiento por el pago de sus servicios. Pero en otros casos, la subastaba al mejor postor y el dinero ingresaba a la tesorería municipal. Varios usuarios fueron despojados de su tanda, así sucedió con Gervacio Ortega quien a pesar de estar en el padrón oficial le quitaron su turno para otorgarlo a un incondicional del presidente municipal. ${ }^{39}$ En el mes de marzo y abril de 1953, más de 30 usuarios reconocidos acusaron al ayuntamiento y al grupo minoritario de "haber sido despojados de su tanda de aguas por 30 personas armadas", las aguas se dieron a vecinos que apoyaban la causa del ayuntamiento. ${ }^{40}$ En todas las denuncias presentadas, el ayuntamiento negó las imputaciones argumentando que era un asunto que no le competía y que se trataba de disputas entre los grupos disiden-

${ }^{38}$ La división interna era evidente, el 17 de marzo de 1951, el mismo Julián Bravo acusó a la Junta de Aguas de cobrar de 140 a 180 pesos por concepto de inscripción para pertenecer a dicha Junta, y de 10 a 15 pesos para que los usuarios disfrutaran de sus tandas. Sin embargo, Froilán Martínez Flores, presidente de la Junta, también demandó a Bravo y solicitó a las autoridades que se investigara el asunto y se comprobara que eran difamaciones. AHA, Aguas Nacionales, c. 1975, exp. 27733, leg. 18.

${ }^{39}$ AHA, Aguas Nacionales, c. 1975, exp. 27733, leg. 18.

${ }^{40}$ AHA, Aguas Nacionales, c. 1976, exp. 27733, leg. 28. 
tes y la Junta Auxiliar de Aguas. Los despojos por parte del grupo minoritario continuaron hasta 1957, y a pesar de que la Junta Auxiliar solicitó la intervención de las autoridades de la SRH, no hubo una respuesta poderosa como se esperaba.

Aunque el Reglamento se publicó en el Diario Oficial el 9 de marzo de 1953, los problemas internos no se resolvieron, algunos usuarios del grupo minoritario encabezados por Rafael Fernández promovieron un juicio de amparo contra la expedición del Reglamento sobre las aguas del manantial La Taza. Y para colmo, continuaron usurpando las tandas de agua y desconociendo a la Junta Auxiliar, tan es así que en marzo de 1958 nombraron a su nueva mesa directiva y enviaron copias a la SRH. Documentación que fue archivada, pues la Secretaría no reconocía a este grupo minoritario y consideraba que su funcionamiento era ilegal.

Los problemas entre el ayuntamiento y la Junta de Aguas no sólo se explican por la pugna entre los líderes locales sino sobre todo por el déficit que imperaba en la tesorería municipal. En 1959, con tal de reunir recursos para aportar 75 mil pesos que le correspondían al municipio por la introducción de la luz eléctrica, el ayuntamiento reconoció que llegó a vender las aguas que administraba para los "Usos públicos y domésticos de la población”.

Nos vimos en la imperiosa necesidad de disponer de 6 horas de esa agua de Usos Públicos y Domésticos para riego, fuera de la ley realizándola económicamente a veces a precio muy bajo, mediano o regular, con lo cual nos fue posible reunir la cantidad de 12,150.00 pesos misma que aparece en el corte de caja anotándose Ingresos por otros conceptos, y si esto se hizo así, es de que estamos sabedores de que dichas aguas son federales y no pueden venderse y de enterarse la SRH nos podían procesar [...] tenemos la satisfacción de que esos dineros recaudados por ese concepto fueron para sufragar en parte la deuda del mismo pueblo. ${ }^{41}$

En su petición manifestaron que fueron acusados por Rosendo Arellano Escobedo, quien controlaba a los usuarios y permitía la

${ }^{41}$ AHA, Aguas Nacionales, c. 1979, exp. 27733, leg. 41. 
venta a acaparadores que se habían enriquecido ilícitamente. ${ }^{42}$ Como todavía tenían una deuda de 13 mil pesos por la "electrificación del poblado" y al no poder reunir esa cantidad, solicitaron a la SRH, "que se nos concediera que continúe esa costumbre ancestral", para sufragar los gastos administrativos de alumbrado público, carretera y centro escolar. Como era de esperarse, la solicitud fue rechazada. El ayuntamiento había perdido su autonomía económica, ahora los ingresos recaudados eran destinados para pagar a los funcionarios de la Junta de Aguas.

La Junta Auxiliar de Aguas del manantial La Taza se formó el 10 de agosto de $1948,{ }^{43}$ pero como hemos visto desde su nacimiento enfrentó múltiples retos, oposiciones, despojos y problemas con otro grupo minoritario que contaba con el respaldo del ayuntamiento. Para empezar carecía de facultades y de la fuerza legal para cobrar las cuotas, en marzo de 1951 el presidente de la Junta se dirigió al Departamento de Aguas dependiente de la Dirección General de Aprovechamientos Hidráulicos manifestando que existían 276 usuarios morosos que debían sus cuotas y, por lo tanto, no existían fondos suficientes para el mantenimiento de la misma Junta como lo establecía el presupuesto de ingresos aprobado por esa Secretaría. La dependencia gubernamental ordenó que se notificara por escrito a los usuarios deudores para que en un plazo no mayor de 15 días se pusieran al corriente de sus pagos, en caso contrario se les suspendería su tanda de agua conforme al artículo 48 del Reglamento vigente para la organización y funcionamiento de las Juntas y Jueces de agua. ${ }^{44}$

Pese a los problemas y retraso de los usuarios, entre el 1 de junio de 1950 y el 30 de abril de 1951 ingresó la cantidad de 3,958.91 pesos, dinero que se destinó para cubrir los salarios de los funcionarios y en menor medida para el mantenimiento del sistema de canales. Para el año siguiente se confiaba en recaudar un mayor ingreso si

${ }^{42}$ Rosendo Arellano Escobedo era sobrino de Zenón Escobedo y fue oficial mayor de la Junta de Aguas desde 1952 hasta 1965. En distintos años fue acusado por varios usuarios por despojarlos de sus tandas de agua para otorgarlas a sus familiares y aliados.

${ }^{43}$ AHA, Aguas Nacionales, c. 1972, exp. 27733, leg. 1. El primer representante de los usuarios fue un tal Rafael Fernández.

${ }^{44}$ AHA, Aguas Nacionales, c. 1975, exp. 27733, leg. 21. 
todos los usuarios pagaban. Por tanto se hizo un presupuesto con base en la cuota anual de 623 usuarios que pagarían nueve pesos cada uno, por recibir una tanda de seis horas cada 41 días ingresarían 5,617 pesos, en cambio, los egresos fueron los siguientes: empleados de la Junta (presidente, secretario, tesorero) recibirían al año 1,825; por cuatro canaleros, 2,920; renta de la casa para oficina 204; gastos de escritorio 360; y gastos extraordinarios 308, lo que daba la suma de 5,617.00. ${ }^{45}$

Otro de los graves problemas fue la tardanza en aprobar el Reglamento, y cuando éste se publicó el 9 de marzo de 1953 en el Diario Oficialy se puso en marcha, varios pueblos se quejaron porque se les disminuyó el volumen de aguas para otorgarlo a nuevos grupos de regantes, por ejemplo, los ejidatarios de San José Buenavista tenían asignados 54 litros por segundo, y ahora estaban recibiendo 37, lo mismo sucedió con los pequeños propietarios de San Francisco Altepexi que entablaron un juicio de amparo contra la expedición y publicación del Reglamento. Por si fuera poco, impidieron el paso de los canales por su territorio, pues dicho Reglamento incluyó a los ejidos de Pantzingo y Chilac, según lo especificaba la respectiva resolución presidencial. Para entonces, los usuarios sumaron el número de 948, lo que provocó que las tandas se extendieran cada 64 días, poniendo en peligro las cosechas. Las discusiones y asambleas para aceptar o no a los nuevos usuarios se prolongaron. La intervención de la SRH y del gobierno poblano resultaron insuficientes y los problemas entre los usuarios de Altepexi contra los ejidos mencionados seguían sin resolverse en 1962.

\section{Conclusiones}

La respuesta de los ayuntamientos ante el proceso de federalización de las aguas en la primera mitad del siglo xx no fue homogénea, los antecedentes históricos y las condiciones socioeconómicas marca-

${ }^{45}$ AHA, Aguas Nacionales, c. 1975, exp. 27733, leg. 22. Cada usuario generalmente poseía una hectárea de terreno de riego y contribuía con 75 centavos mensuales por una tanda de 6 horas. 
ron los contrastes regionales. Como hemos visto, en algunos municipios del Valle de Teotihuacan, las aguas de los manantiales estaban en poder de las haciendas desde la época colonial y, para principios del siglo xx, el ayuntamiento no recibía ingresos por el ramo de aguas ya que dependía de otros rubros para sufragar sus gastos administrativos, por tanto, no se interesó en defenderlas. En cambio, el ayuntamiento de San Gabriel Chilac, Puebla, había logrado mantener como comunales una porción considerable de las aguas del manantial La Taza durante el periodo colonial, el siglo XIX y la primera mitad del siglo xx. La mayor parte de sus ingresos provenía del ramo de aguas y alrededor de este recurso llegó a girar la organización cívica religiosa de la comunidad.

En ambas regiones, la desamortización de la propiedad civil consolidó la pequeña propiedad, tan es así que a mediados del siglo Xx los pequeńos propietarios eran los principales usuarios de las aguas y, en consecuencia, los productores agrícolas más exitosos.

La declaración de las corrientes de agua como federales desde la Ley General de Vías de Comunicación de 1888 hasta el artículo 27 de la Constitución de 1917 obligó a hacendados y empresarios a ajustarse a las nuevas reglas legales. En cambio, ciertos municipios que todavía dependían de los ingresos de aguas comunales se resistieron, es el caso de San Gabriel Chilac que opuso una resistencia enorme a la federalización, en primer lugar, porque gran parte de sus ingresos provenían del ramo de aguas; en segundo, porque los funcionarios del gobierno local eran compensados con una tanda de aguas que podían vender; y en tercero, porque defendían su autonomía municipal. En tanto, el municipio de San Juan Teotihuacan no tuvo ningún acicate para tratar de defender o recuperar las aguas de los manantiales, porque desde el siglo xIx las habían perdido y además porque contaba con otros recursos fiscales. Esta diferencia marcó profundos contrastes, mientras en Teotihuacan la federalización de las aguas fue relativamente pronto y los ejidatarios desplazaron a los hacendados en los usos de las aguas desde 1927 cuando se constituyó la Junta de Aguas y se estableció un Reglamento. En San Gabriel Chilac, el ayuntamiento mantuvo una tenaz oposición hasta 1949 cuando se fundó la Junta Auxiliar de Aguas y todavía des- 
pués de la publicación del reglamento en 1953 que consideró a ejidatarios, pequeńos propietarios y pueblos.

Tanto en una región como en otra, a pesar de los nuevos reglamentos, los conflictos entre los usuarios prosperaron. La Junta de Aguas de los manantiales de Teotihuacan incluyó a nuevos regantes, lo que trajo consigo mayores problemas en la redistribución de las aguas, pero a diferencia del pasado, los pleitos por el acceso de las aguas ya no se darían entre pueblos y haciendas sino entre ejidatarios, pequeños propietarios y avecindados. En otras palabras, el Reglamento de Aguas de 1927 terminó con la supremacía de los hacendados sobre las fuentes de agua y, por si fuera poco, el reparto ejidal representó la caída de los latifundios, estos actos dieron el golpe mortal a los hacendados, pues en adelante solamente podrían utilizar alrededor de $15 \%$ del total de aguas y someterse a las decisiones de la Junta (González 2000, 139-140). En este proceso, mucho tuvo que ver la ley de aguas de 1929, la cual modificaba radicalmente la de 1910, esta última consideraba como únicos sujetos de derecho a solicitar aguas a las empresas. En cambio, la ley de 1929 contempló a los nuevos actores que surgieron de la reforma agraria (Aboites 1998, 135-138).

La situación social y económica de ambos municipios marcó algunos contrastes, mientras el ferrocarril y otros síntomas del desarrollo económico porfirista llegaron a Teotihuacan desde fines del siglo xIx, el municipio de San Gabriel Chilac permaneció relativamente aislado y fue hasta la década de 1920 cuando surgieron ejidos y pocos ańos después se introdujeron nuevos cultivos para exportación que reclamaron derechos al uso de las aguas del manantial, lo que alteró la organización del antiguo sistema comunal y trajo consigo escisiones entre los líderes locales que se disputaron el control social, político y económico del municipio, a tal grado que unos se refugiaron en la Junta Auxiliar de Aguas y otros se apoderaron del ayuntamiento y desde estas instancias continuaron su lucha interna en menoscabo de la mayoría de los usuarios.

Tanto en el Valle de Teotihuacan como el de Tehuacán, Puebla, al mismo tiempo que se formaron ejidos, también se introdujeron nuevos cultivos comerciales como alfalfa, árboles frutales, legum- 
bres y hortalizas que fueron sustituyendo no sólo a los productos tradicionales de maíz, trigo y frijol, sino a la par fueron desplazando las formas de organización comunitaria, por si fuera poco, se establecieron fábricas y empresas agropecuarias que demandaron mayores volúmenes de agua. El aumento de la población provocó más disputas por el acceso al vital líquido y la búsqueda de nuevas fuentes de agua. La solución inmediata fue la apertura de pozos profundos en el Valle de Teotihuacan, sin embargo, el incremento demográfico, la apertura del drenaje, la construcción de casas sobre los canales trajo consigo desde la contaminación y disminución de los mantos freáticos hasta una aguda competencia y su desecación en 1991. El sistema de riego que había persistido desde el periodo colonial hasta antes de la reforma agraria, en manos de pueblos y haciendas y con una producción orientada al mercado de autoconsumo regional, sufrió profundas modificaciones con el aumento de regantes y la implementación de la moderna tecnología, uso de fertilizantes y monocultivos que sustituyeron los pluricultivos y, en consecuencia, alteraron de manera profunda no solo la economía sino el ecosistema del valle. En contraste, en San Gabriel Chilac se abrieron galerías filtrantes, pero lejos del nacimiento del manantial, lo que impidió la disminución de las aguas, de tal forma que el sistema de riego comunitario aunque perdió sus rasgos colectivos prevaleció en manos de los pequeños propietarios, quienes introdujeron otros cultivos comerciales y los exportaron a los mercados nacionales.

Por último, los casos de Chilac y Teotihuacan ponen en evidencia la organización efectiva de los antiguos sistemas de pequeńo riego que se trasformaron con la reforma agraria y sus políticas de irrigación, en el caso de Teotihuacan se perdió el control sobre el medio ambiente y de manera drástica se agotaron los manantiales milenarios, en cambio en Chilac, a pesar de las problemas y las divisiones internas, el manantial La Taza ha seguido produciendo agua hasta el presente, por supuesto no exento de problemas entre los diversos usuarios.

En suma, el gobierno federal estableció nuevas reglas del juego, por el lado de las aguas excluyó a las autoridades municipales creando Asociaciones de Usuarios y Juntas de Aguas, por el lado de las tierras, en el caso de la dotación se creó la figura del Comisariado 
ejidal, en el caso de la restitución la del Comisariado de Bienes Comunales. Estas nuevas instituciones quedaron bajo la batuta del ejecutivo federal y fueron las que tomaron las riendas para imponer multas, establecer reglamentos, otorgar permisos y cobrar cuotas en cuestión de aguas y tierras y, en suma, desplazaron al ayuntamiento de sus atributos y antiguas funciones sociales.

\section{SigLAS Y REFERENCIAS}

AGA, Archivo General Agrario, México.

AHA, Archivo Histórico del Agua, México, D. F.

AHMTEO, Archivo Histórico Municipal San Juan Teotihuacan, México.

\section{BiBLIOGRAFÍA}

Авогтеs, Luis, La decadencia del agua de la nación. Estudio sobre desigualdad social y cambio politico en México (segunda mitad del siglo XX), México, El Colegio de México, 2009.

Авогтеs, Luis, El Agua de la nación. Una historia politica de México (1888-1946), México, Ciesas, sep, 1998.

Aвогтеs, Luis y Valeria Estrada, comps., Del agua municipal al agua nacional. Materiales para una historia de los municipios en México, 1901-1945, México, Aна, Ciesas, Colmex, 2004.

BirRICHAGA, Diana, "Administración de tierras y bienes comunales. Política, organización territorial y comunidad de los pueblos de Texcoco, 1812-1857", Tesis de doctorado en Historia, México, El Colegio de México, 2003.

BirRichaga, Diana, "Reconstrucción histórica de los sistemas hidráulicos de Texcoco, siglo xIx", Boletín del Archivo Histórico del Agua, 20, 7, 2002, 11-20.

CAMACHo Pichardo, Gloria, "Desamortización y reforma agraria. Los pueblos del sur del valle de Toluca, 1856-1930", Tesis de doctorado en Historia, México, El Colegio de México, 2006.

Cárdenas Lanz, José, Legislación de aguas en México. Estudio histórico, 1521-1981, tomo I, México, Consejo Nacional del Gobierno del Estado de Tabasco, 1982. 
CASTAÑEDA, Rocío, Irrigación y reforma agraria. Las comunidades de riego del Valle de Santa Rosalía, Chibuahua, 1920-1950, México, Ciesas, 1995.

Chávez Cruz, María del Carmen, "Entre el ayuntamiento y el gobierno federal. El arrendamiento de los manantiales Las Fuentes, Jocotitlán, Estado de México. 1916-1932”, Boletín del Archivo Histórico del Agua, 30, 10, 2005, 20-29.

Doolittle, William, Canales de riego en el México prehistórico. La secuencia del cambio tecnológico, México, Universidad Autónoma de Chapingo, 2004.

Gamio, Manuel, La población del Valle de Teotihuacán, 5 tomos, México, Instituto Nacional Indigenista, 1979.

GonzÁlez Huerta, Margarita, "El sistema de riego de los manantiales de San Juan Teotihuacan”, en Jacinta Palerm y Tomás Martínez Saldaña, comps., Antología sobre pequeño riego. Organizaciones Autogestivas, vol. II, México, Colegio de Postgraduados, Plaza y Valdés, 2000, 133-210.

Henao, Emilio, Tehuacán. Campesinado e irrigación, México, EDICOL, 1980.

Herrera y LASSO, José, Apuntes sobre irrigación, notas sobre su organización económica en el extranjero y en el pais, México, Ciesas, IMTA, 1994.

Mendoza García, Edgar, "Galerías filtrantes: la disputa por el agua del subsuelo en el valle de Tehuacán, 1900-1930”, en Martín Sánchez Rodríguez, J. M. Durán y Antonio Escobar Ohmstede, comps., El agua en la historia: balance y perspectivas, México, El Colegio de Michoacán, Universidad Autónoma de Guadalajara, 2005, 221-238.

Palerm, Jacinta, Tomás Martínez Saldaña y Francisco EscobeDO, "Modelo de investigación: organización social de sistemas de riego en México", en Jacinta Palerm y Tomás Martínez Saldaña, comps., Antología sobre pequeño riego. Organizaciones Autogestivas, vol. II, México, Colegio de Postgraduados, Plaza y Valdés, 2000, 31-61.

Pérez Chávez, Mario, "Mapa de vegetación y uso del suelo en la porción sur del valle de Tehuacán”, en Geografía, v, 6, INEGI. s.f. 
Salazar Exarre, Celia, Uso y distribución del agua en el Valle de Teotihuacan. El caso de San Juan Bautista Axalpan, Puebla 16101798, México, INAH, 2000.

SAndre Osorio, Israel, "Del derecho colonial al derecho municipal: la distribución de las aguas del Río Cuautitlán, 1762-1914", Boletín del Archivo Histórico del Agua, 12, 2007, 35-49.

FECHA DE RECEPCIÓN DEL ARTÍ́CUlo: 22 de julio de 2011 FECHA DE RECEPCIÓN DE LA VERSIÓN FINAL: 10 de enero de 2013 